The luminance ratio also accounts for other results with randomized equal-energy flashes. Bernstein, Futch, and Schurman (1973). Kietzman and Gillam (1972), and Lewis (1964) used small ratios between 1.2 and 4 when they found that Bloch's law held. The latter two studies suggest a luminance effect.

When energies, but not equal energies, were randomized, larger ratios of 3.4 to 10 produced failures of Bloch's law (Grossberg, 1968, 1970a; Raab \& Fehrer, 1962). Partial randomization was used in a more recent study where "equally detectable equal-energy flashes had different RTs [Bruder \& Kietzman, 1973, p. 299]," as Grossberg found; however, Bloch's law held for some RTs. Of these, RTs for ratios of 8.8 to 28 suggest a luminance effect; Bruder (1971) noted that the less intense flashes "yielded longer median RTs than would be expected if there were complete reciprocity [p. 79]." The RTs for smaller ratios, 3.4 to 9.2 , were not discernibly ordered. These ratios seem large, but the RTs had quartile deviations of about 40 to $130 \mathrm{~m} \mathrm{sec}$, large compared with Grossberg's 20 to $70 \mathrm{msec}$.

Thus, the luminance ratio is a valid rough index for comparing data on RT in relation to Bloch's law-still one more suggestion that luminance plays a special role.

\section{REFERENCES}

Bernstein, I. H., Futch, D. G., \& Schurman, D. L. Some exposure duration effects in simple reaction time. Journal of Experimental Psychology, 1973, 97, 317-322.
Bruder, G. E. The temporal integration of luminous energy for response frequency, response latency, and signal detectability. Unpublished doctoral dissertation, The City University of New York, 1971 .

Bruder, G. E., \& Kietzman, M. L. Visual temporal integration for threshold, signal detectability, and reaction time measures. Perception \& Psy chophysics, 1973, 13, 293-300.

Grossberg, M. The latency of response in relation to Bloch's law at threshold. Perception \& Psychophysics, 1968, 4, 229-232. Grossberg, M. Frequencies and latencies in detecting two-flash stimuli. Perception \& Psy chophysics, 1970a, 7, 377-380.

Grossberg, M. "Backward masking" of simple detection latencies. Perception \& Psychophysics, 1970b, 8, 308-312.

Hildreth, J. D. Bloch's law and a temporal integration model for simple reaction time to light. Perception \& Psychophysics, $1973,14,421-432$

Hufford, L. E. Reaction time and the retinal area-stimulus intensity relationship. Journal of the Optical Society of America, 1964, 54, 1368-1373.

Kietzman, M. L., \& Gillam, B. J. Visual temporal integration and simple reaction time. Perception \& Psychophysics, 1972, 11 , 333-340.

Lewis, M. F. Magnitude estimation and reaction time as functions of flash luminance and duration in the fovea. Unpublished doctoral dissertation, Columbia University, 1964

Pease, V. P. Effect of luminance and duration of interstimulus interval upon human reaction time. Journal of the Optical Society of America, 1972,62, 1505-1507.

Raab, D., \& Fehrer, E. The effect of stimulus duration and luminance on visual reaction time. Journal of Experimental Psychology, 1962, 64, 326-327.

Teichner, W. H., \& Krebs, M. J. Laws of the simple visual reaction time. Psychological Review, 1972, 79, 344-58.

(Received for publication April 15, 1974.)

\title{
Monitoring small eye movements with averaged EOG*
}

\author{
ROBERT L. COLEGATE $\dagger$ and JAMES E. HOFFMAN \\ University of Illinois, Champaign, Illinois 61820
}

\begin{abstract}
The feasibility of measuring small ( 1 to $1 \frac{1 / 2}{d e g}$ of visual angle) eye movements by averaged EOG was investigated. Latencies and amplitudes obtained by this procedure were in good agreement with results reported using other methods.
\end{abstract}

One method of investigating selective attention during a fixation involves tachistoscopically presenting a letter array greater than S's capacity to report all accurately. Attention is manipulated by designating a selected portion of the display for report. Tachistoscopic exposure is an implicit control for eye movements but unfortunately restricts the values of temporal parameters.

An ongoing line of research involves presenting a

*This paper was sponsored by Charles W. Eriksen, who takes full editorial responsibility for its content. This investigation was supported by United States Public Health Service Research Grant MH-1206 and United States Public Health Service Research Career Program Award No. K6-MH-22014 and Predoctoral Fellowship 1-F01-MH-47201-01.

tR equests for reprints should be made to Robert L. Colegate, Department of Psychology, Norfolk State College, Norfolk, Va. 23504 . black bar indicator, which designates one position of a multiletter display for report, at various stimulus onset asynchronies (SOA) prior to the presentation of the display. The dependent variable is voice reaction time (RT), which decreases as the indicator precedes the display (Eriksen \& Hoffman, 1972). One of the questions under investigation is the determination of an SOA value where RT is asymptotic for each of several display sizes. The manipulation of SOA and the exposure durations required for relatively low error RT make necessary a means of assessing eye movements.

Electrooculograms (EOG) have long been used to record large eye movements in a relatively free situation. EOGs to eye movements of $1 \mathrm{deg}$ of visual angle or less have only been recorded where a bitebar has been used or where the external epidermis has been removed to 
Table 1

\begin{tabular}{|c|c|c|c|c|c|}
\hline \multirow[t]{2}{*}{ Panel A } & \multicolumn{2}{|c|}{$\begin{array}{l}\text { Eye Movement } \\
\text { S R.C. }\end{array}$} & \multicolumn{2}{|c|}{$\begin{array}{c}\text { Latency (Msec) } \\
\text { S J.H. } \\
\end{array}$} & \\
\hline & $\begin{array}{l}\text { NEAR } \\
\text { (1 Deg) }\end{array}$ & $\begin{array}{c}\text { FAR } \\
\left(1 \frac{1}{2} \text { Deg }\right)\end{array}$ & $\begin{array}{l}\text { NEAR } \\
\text { (1 Deg) }\end{array}$ & $\begin{array}{c}\text { FAR } \\
\left(1 \frac{1}{2} \text { Deg }\right)\end{array}$ & \\
\hline & $\begin{array}{l}290 \\
210 \\
280 \\
300 \\
280 \\
280\end{array}$ & $\begin{array}{l}250 \\
280 \\
260 \\
290 \\
250 \\
280\end{array}$ & $\begin{array}{l}190 \\
180 \\
176 \\
176 \\
190 \\
190\end{array}$ & $\begin{array}{l}180 \\
175 \\
190 \\
176 \\
190 \\
190\end{array}$ & \\
\hline Mean & 273 & 268 & 184 & 184 & \\
\hline Panel B & \multicolumn{4}{|c|}{ Voicing Latency $(\mathrm{Msec})$} & \\
\hline $\begin{array}{c}\text { Move } \\
\text { (NEAR) }\end{array}$ & $\begin{array}{l}\text { Fixate } \\
\text { (NEAR) }\end{array}$ & $\begin{array}{l}\text { Fixate } \\
\text { (CEN- } \\
\text { TER) }\end{array}$ & $\begin{array}{c}\text { Move } \\
\text { (NEAR) }\end{array}$ & $\begin{array}{l}\text { Fixate } \\
\text { (NEAR) }\end{array}$ & $\begin{array}{l}\text { Fixate } \\
\text { (CEN- } \\
\text { TER) }\end{array}$ \\
\hline $\begin{array}{l}832 \\
859\end{array}$ & $\begin{array}{l}580 \\
608\end{array}$ & $\begin{array}{l}564 \\
593\end{array}$ & $\begin{array}{l}591 \\
675\end{array}$ & $\begin{array}{l}449 \\
442\end{array}$ & $\begin{array}{l}437 \\
438\end{array}$ \\
\hline Mean 846 & 595 & 579 & 633 & 445 & 438 \\
\hline \multirow[t]{3}{*}{ Panel C } & \multicolumn{4}{|c|}{$\begin{array}{c}\text { Amplitude of Eye Movement (MicroV) } \\
\text { S R.C. } \\
\end{array}$} & \\
\hline & $\begin{array}{r}\text { NEAR } \\
(1 \mathrm{Deg})\end{array}$ & $\begin{array}{c}\text { FAR } \\
\left(1^{1 / 2} \text { Deg) }\right.\end{array}$ & $\begin{array}{r}\text { NEAR } \\
(1 \text { Deg) }\end{array}$ & $\begin{array}{c}\text { FAR } \\
\left(1 \frac{1}{2} \text { Deg }\right)\end{array}$ & \\
\hline & $\begin{array}{l}16 \\
21 \\
16 \\
11 \\
17 \\
14\end{array}$ & $\begin{array}{l}28 \\
18 \\
26 \\
31 \\
21 \\
26\end{array}$ & $\begin{array}{l}21 \\
18 \\
24 \\
21 \\
27 \\
24\end{array}$ & $\begin{array}{l}33 \\
22 \\
35 \\
31 \\
40 \\
34\end{array}$ & \\
\hline Mean & 16 & 25 & 23 & 33 & \\
\hline
\end{tabular}

reduce background electrical activity (Schackel, 1961). In the experimental setting described above, eye movements of 1 deg of visual angle must be monitored without the use of a bitebar or abrasive skin preparation.

In the present study, the feasibility of using an averaged EOG in this experimental setting was determined. The rationale is as follows. A single EOG contains the dc shift in polarity of the corneal-retinal potential as well as the background activity which may frequently obscure that due to a small eye movement. If it is assumed that only the former is time-locked to the stimulus, then the background activity will have a mean of zero at any point in time during the averaging epoch when averaged over several trials. That portion of the EOG due to the change in the corneal-retinal potential will have the same polarity at every point in time on each trial, and the averaged record will represent its mean amplitude.

\section{METHOD}

\section{Subjects}

The two authors served as Ss. Both had normal or corrected to normal vision.

\section{Apparatus and Stimuli}

Stimuli were displayed in a Scientific Prototype Model GA three-field tachistoscope. Luminances of each of the three fields were set at $6 \mathrm{fL}$ and monitored with a Spectra spot photometer. Eye movements were recorded from five Beckman electrodes affixed with Beckman electrode paste and adhesive collars. The electrodes were located above and below the right eye (vertical) and at the right and left lateral canthi (horizontal). A ground electrode was centered on the forehead. Electrode resistances were always $5,000 \mathrm{ohms}$ or less.

The electrodes were input to a Grass Model 79 ac amplifier set to a sensitivity of $20 \mathrm{microV} / \mathrm{cm}$. The $1 / 2$ amplitude bandpass was .15 to $15 \mathrm{~Hz}$. The output of the amplifier was fed into a Fabritek $1052 \mathrm{H}$ signal averager and monitored with a Tektronix oscilloscope. A trigger pulse was obtained for the averager by using the S's start switch to gate a Tektronix 162 waveform generator and 161 pulse former.

The S's start switch also started an auxilliary timer on the tachistoscope whose duration was set to yield a $200-\mathrm{msec}$ prestimulus interval between switch closure and onset of the stimulus field containing the target letter. It simultaneously started a Hunter Model 1522 digital clock set to display RT in milliseconds. A microphone located below the S's viewer triggered a Scientific Prototype Model 761-G voice relay which stopped the clock.

The stimuli were the black letters $\mathrm{A}, \mathrm{H}, \mathrm{U}$, and $\mathrm{M}$ mounted on white vinyl cards. The fixation point was a black plus sign mounted on a white vinyl card. Both the letters and the fixation point subtended $.2 \mathrm{deg}$ of visual angle and were obtained from Paratipe No. 11316 pressure lettering sheets.

There were three conditions of stimulus location. In the NEAR (FAR) conditions a single letter was located at $1\left(1^{1 / 2}\right) \mathrm{deg}$ of visual angle of horizontal or vertical displacement from the central fixation point. In the CENTER condition a single letter occurred at a location .1 deg of visual angle above the center of the fixation point.

\section{Procedure}

A pilot experiment was conducted to determine the feasibility of averaging the two horizontal and two vertical directions of eye movement together. This pilot work indicated that all four directions had similar latencies and waveforms. These directions were mixed by switching and reversing the polarities of the appropriate set of electrodes on the amplifier by means of the input selector before each trial.

Each $\mathrm{S}$ served in two experimental sessions. The first session was devoted to determining the feasibility of averaging small eye movements. There were two instruction conditions: "maintain fixation" and "move your eyes." In the eye movement condition, the fixation point was turned off when the letter was presented. Each position occurred equally of ten under both NEAR and FAR conditions. In the fixation condition, the cross remained on and a blank white vinyl card was presented instead of a NEAR or FAR stimulus card. Fixation and movement conditions were run in separate blocks.

Ss were instructed to get the fixation point in good focus. When the $\mathrm{E}$ determined that fixation was steady, the ready signal was given and $\mathrm{S}$ initiated a trial by closing a microswitch. After a 200-msec prestimulus interval, a letter was presented and $\mathrm{S}$ brought it into central fixation as quickly as possible. Averaging was done over an epoch of $1,024 \mathrm{msec}$.

In the second session, additional data were collected on the above conditions. The effect of making a vocal response to the presented letter was $2^{\prime}: c$ investigated by instructing the $S$ to voice the letter as quickly as possible while either maintaining fixation (fix-voice) or changing fixation to the letter and naming it (move-voice). Separate blocks of trials were run under two conditions of stimulus location (CENTER and NEAR) within the fix-voice instruction condition. Two blocks of 16 trials each were run for each condition. The stimulus location condition was NEAR for the move-voice instructions.

Latencies of movement were determined by judging from the averaged record the point at which the movement wave began. Size of the eye movement was determined by measurement of 
the maximum departure of the eye movement wave from the baseline established by the $200-\mathrm{msec}$ prestimulus interval. In order to calibrate the records, a 50-microV pulse obtained from the calibration unit on the preamplifier was sent through the recording and averaging system.

\section{RESULTS AND DISCUSSION}

Eye movement latencies, voicing latencies, and the amplitudes of the averaged EOGs are presented in Table 1 for each block of trials under all stimulus location and instruction conditions. Eye movement tracings illustrating the quality of the record are presented in Figs. 1 and 2.

The movement records are clearly distinguishable from the fixation blocks and also reveal an effect of extent of movement. The average maximum departure from baseline for each $\mathrm{S}$ is proportional to the extent of stimulus displacement from fixation. The mean amplitude of records obtained from the FAR condition $\left(1 \frac{1 / 2}{2}\right)$ is equal to 1.56 times the amplitude of the mean NEAR (1) record for S R.C. and equal to 1.43 times the amplitude of mean NEAR record for S J.H. The latencies for both conditions are comparable and are in good agreement with results reported by Saslow (1967). Further, the mean values of 16 and 23 microV from the NEAR condition are consistent with results reported

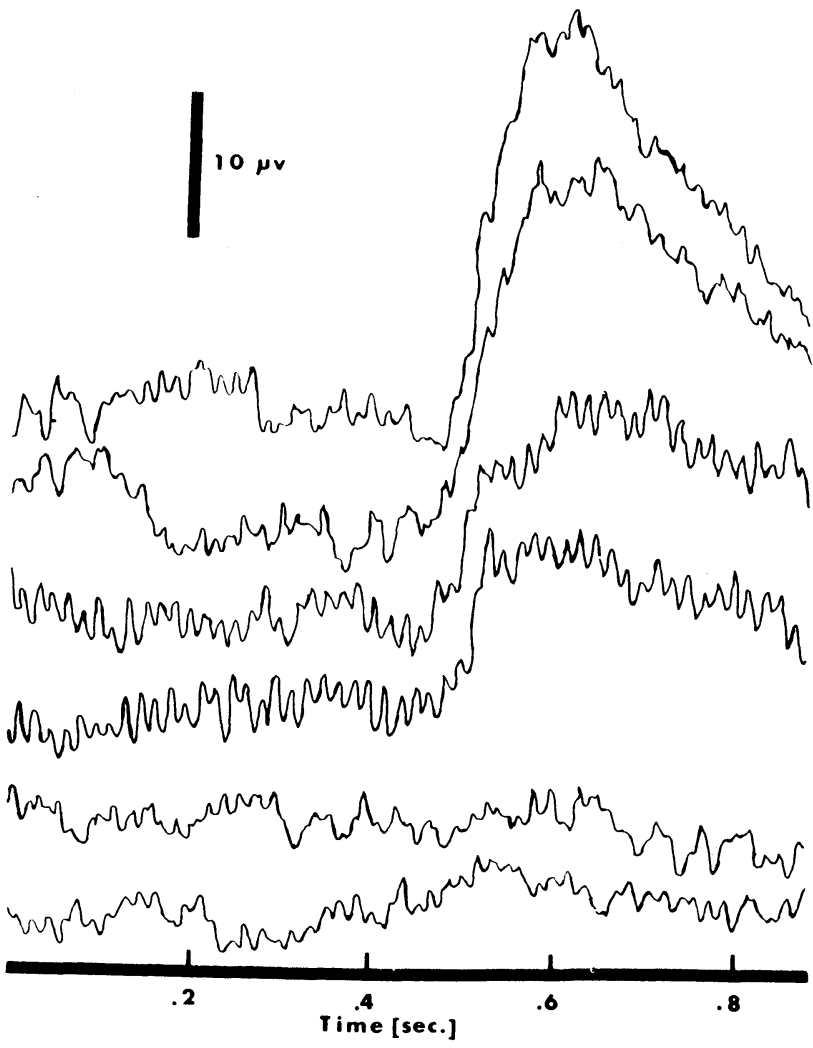

Fig. 1. Averaged EOGs for S R.C. FAR stimulus location-upper two tracings; NEAR stimulus location-middle two tracings; fixation condition-lower two tracings. The stimulu s onset at .2 sec.

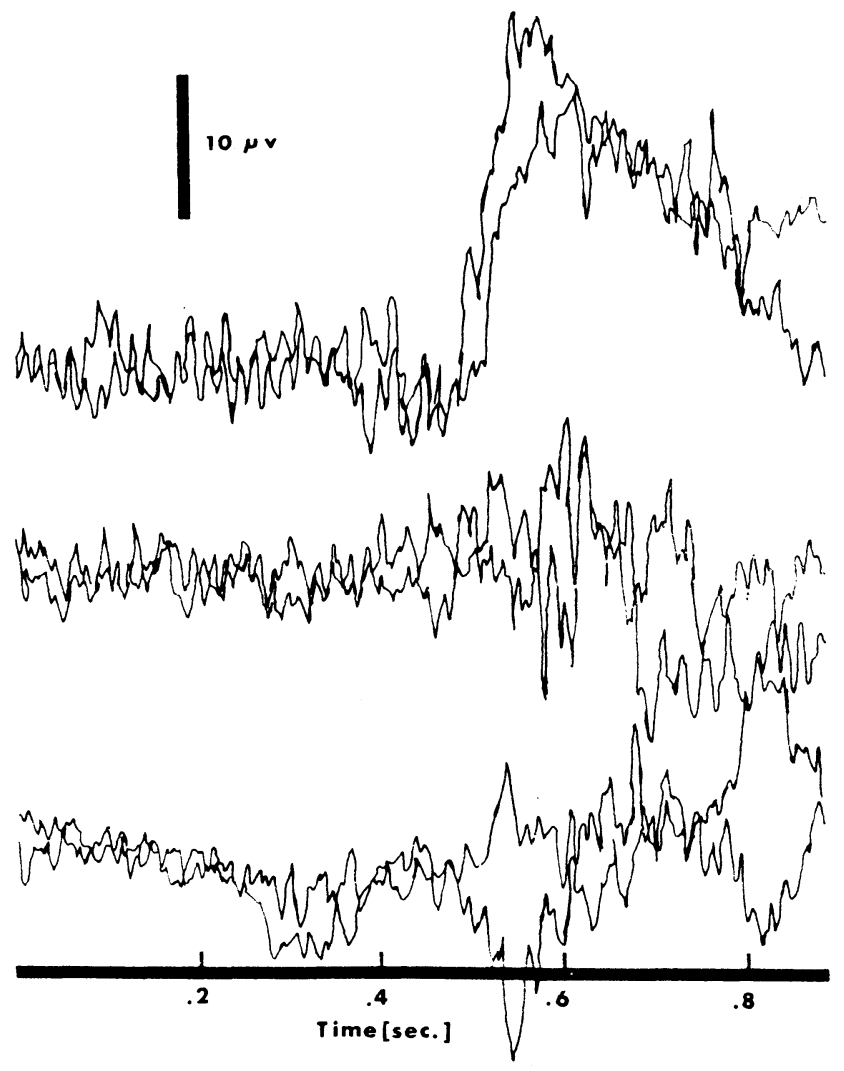

Fig. 2. Averaged EOGs for S R.C. under instructions to name the let ter. Move (NEAR)-upper two tracings; fixate (CENTER)-middle two tracings; fixate (NEAR)-lower two tracings. The stimulus onset at .2 sec.

elsewhere (Schackel, 1961).

Also apparent in the records is a component due to the voicing of the letter. This same activity is present in the move-voice condition but occurs later in time. The clearly differentiable waveforms arising from movement and voicing make it possible to determine in RT tasks whether eye movements are a necessary antecedent to attentional selection.

These results indicate that an averaging procedure is a feasible solution to the problem of measuring small eye movements ( 1 to $1 \frac{1 / 2}{2}$ deg of visual angle in extent). The finding of different waveforms due to movement and voicing components makes the approach attractive for investigating the role of eye movements in recent RT studies of visual selective attention.

\section{REFERENCES}

Eriksen, C. W., \& Hoffman, J. E. Some characteristics of selective attention in visual perception determined by vocal reaction time. Perception \& Psychophysics, 1972, 11, 169-171.

Saslow, M. G. Latency for saccadic eye movements. Journal of the Optical Society of America, 1967, 57, 1030-1033.

Schackel, B. Electro-oculography: The electrical recording of eye position. In Proceedings of the Third International Conference on Medical Electronics. London: Institute of Electrical Engineers, 1961. Pp. 323-335.

(Received for publication April 29, 1974.) 